\section{Review Article}

Ann Liver Transplant 2021;1(2):113-122

https://doi.org/10.52604/alt.21.0018

Check for updates
Annals of Liver Transplantation

pISSN $2765-5121$

eISSN 2765-6098

\title{
Liver transplantation in Wilson's disease: A systematic review
}

\author{
Emre Turgut, Cemalettin Aydin, Cuneyt Kayaalp, Sezai Yilmaz
}

Department of Gastrointestinal Surgery, University of Inonu Faculty of Medicine, Malatya, Turkey

Received June 2, 2021

Revised July 29, 2021

Accepted August 1, 2021

Published online August 19, 2021

Corresponding author: Emre Turgut Department of Gastrointestinal Surgery, University of Inonu Faculty of Medicine, Malatya 44210, Turkey

E-mail:dr.emrtrgt@gmail.com

https://orcid.org/0000-0001-8196-1871

(c) The Korean Liver Transplantation Society (c) (1) \& This is an Open Access article distributed under the terms of the Creative Commons Attribution Non-Commercial License (http://creativecommons.org/licenses/by-nc/4.0/) which permits unrestricted non-commercial use, distribution, and reproduction in any medium, provided the original work is properly cited.

\begin{abstract}
Wilson's disease (WD) is a rare genetic disorder affecting the metabolism of copper that may present with neurological symptoms. In cases leading to hepatic failure, liver transplantation (LT) may be necessary. The aim of this paper is to examine the literature on LT cases related to WD in terms of disease characteristics, the neurological conditions of patients and survival rates. The keywords "Wilson and transplant ${ }^{\star}$ " were used to perform a title and abstract search across three databases (PubMed, Scopus, Web of Science) up until November 2018. The results from a total of 791 patients, mentioned in 28 studies, were analyzed. Thirty-nine point six percent of the patients received emergency $L T$ and acute liver failure was more predominant in woman patients $(61.7 \%-38.3 \%$; $p<0.0001)$. Live donations accounted for $36.6 \%$ of the transplants with none of these patients experiencing recurrence of disease. $36.4 \%$ of the patients displayed neurological symptoms prior to the transplant; however, following the operation these symptoms decreased by $74.2 \%$. Survival rates for $1,2,3,5,10$ years were $84 \%, 82 \%, 81 \%, 81 \%$, and $80 \%$, respectively. Further research into the reasons that acute liver failure in patients suffering from WD is more common among women is needed. Moreover, while mortality rates for up to one-year post-transplant are $16 \%$, this rate is only $4 \%$ for the following $1-10$ years. As neurological symptoms experienced prior to transplantation decrease by $74.2 \%$ after the operation, further studies should be carried out into the factors that determine potential neurological improvement.
\end{abstract}

Keywords: Liver; Transplantation; Review

\section{INTRODUCTION}

Wilson's disease (WD) is a genetic disorder affecting the metabolism of copper. The disease is caused by the mutations of homozygous or conjugated heterozygote (presence of two different mutant alleles) found in the ATP7B gene. This gene encodes the transmembrane copper carrier ATPase 2 which enables copper to enter the biliary tract for the synthesis of ceruloplasmin (the major copper-carrying protein in the blood) [1]. In a Wilson's patient, the mutated ATP7B gene causes the copper to accumulate in the hepatocytes, as it cannot be released into the biliary tract. Excess copper detached from the ceruloplasmin also causes serious neuropsychiatric symptoms in secondary tissue such as the brain. The symptoms of this illness are varied and mostly develop between the 1 st and 4 th decades of life [2] with a prevalence of symptomatic disease of 1 in 30,000 people [3]. While most patients can be maintained 
with medical treatment, $5 \%$ develop acute liver failure (ALF) and $10 \%$ chronic liver failure (CLF) [4]. Liver transplantation (LT) can therefore be a lifesaving solution for such Wilson's patients. The first case of liver transplant on a WD patient was published in 1971 [5] and since that time substantial progress in the usage of LT has been made. In the USA, $0.5 \%-1.5 \%$ of all LT performed are WD related $[6,7]$. In addition to hepatic insufficiency, LT is also important in terms of neurological complications. Post-transplant improvements have been recorded in patients with serious neurological symptoms [8]. However, LT-related complications and inconsistencies in post-transplant neurological improvement cast doubt on the validity of recommending neurological symptoms alone as indication for LT. In this study, all cases of LT in WD patients mentioned in the literature were analyzed in terms of demographic characteristics, indications for transplantation, pre-transplantation neurological status, transplantation results, neurological improvement and post-transplant survival rates.

\section{MATERIALS AND METHODS}

\section{Screening Strategy and Inclusion Criteria}

A systematic review of all publications containing findings of LT related to WD was carried out. Using the keywords "Wilson and transplant*", three databases (PubMed,
Scopus, Web of Science) were scanned. Starting from the first recorded case, all publications until November 2018 were analyzed. Only English-language clinical trials were included in this study. Reviews, meta-analyses, case reports, poster presentations and non-human clinical studies were excluded from this review.

\section{Data Extraction}

Data extraction was completed by two authors, guided by a previously created database. The following data was recorded in the database: article name, first author name, country, center, year, type of study, number of patients, average age, patient group (pediatric or adult), gender, transplantation indication (CLF or ALF), presence of KayserFleischer rings (KF), biochemical levels, neurological status pre-operative and post-operative, donor status (live, cadaver), post-transplant rejection and re-transplantation rates, causes of perioperative mortality and survival rates for 1,2 , 3,5 , and 10 years.

\section{Statistical Method}

Statistical analysis was conducted using MedCalc software (MedCalc Software, Ostend, Belgium). Both random-effect and fixed-effect models were to combine the studies and to determine the yearly mortality proportion \%, and the $95 \%$ confidence interval. Statistical heterogeneity

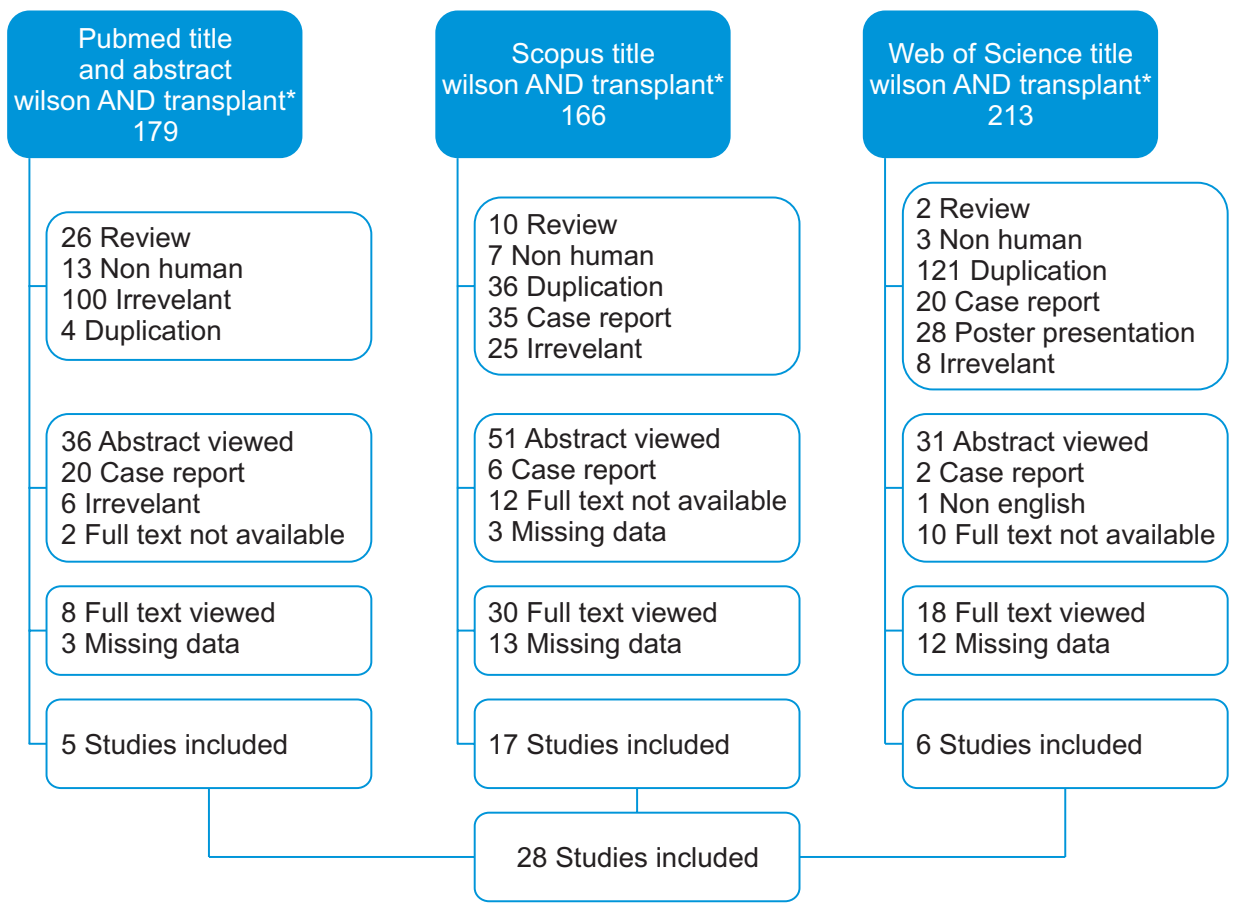

Fig. 1. Flowchart. 
of included studies was tested using $\mathrm{I}^{2}$ statistics. Publication bias was tested by Egger's weighted regression method and a p-value $<0.05$ was considered indicative of statistically significant publication bias.

\section{RESULTS}

During the initial screening 558 publications were found. After excluding recurring results, 399 publications remained. The selection process can be seen in Fig. 1. Twenty-eight clinical trials performed between 1993-2018 were also included in this study [7-34]. All the studies were retrospective and their parameters can be found in Table 1 and 2.

The average age of the 26 cases where age was mentioned was $21.4(11-32)$ years. Two studies involved pediatric patients, 7 comprised adults and the remaining 19 focused on mixed groups of patients. In 18 detailed studies, a total of 216 (37.7\%) pediatric and 356 (62.2\%) adult patients were included. According to 25 studies that indicated gender, 393 (51.7\%) patients were woman and 366 (48.2\%) man. The average follow-up duration of the 20 studies that included this parameter, was 62.5 months. In total, 791 patients received a LT due to WD.

Table 1. General features of the studies and patient characteristics

\begin{tabular}{|c|c|c|c|c|c|c|}
\hline First author & Year & Country & No. of patients & Child/adult & Woman/man & Mean age (yr) \\
\hline Rela M & 1993 & UK & 12 & NA & $8 / 4$ & 19 \\
\hline Schilsky M & 1994 & USA & 55 & NA & $32 / 23$ & 23.1 \\
\hline Bellary S & 1995 & USA & 39 & $16 / 23$ & NA & 23 \\
\hline Chen $\mathrm{CL}$ & 1997 & Taiwan & 7 & $0 / 7$ & $4 / 3$ & 21.4 \\
\hline Haberal M & 1999 & Turkey & 8 & NA & NA & 23.3 \\
\hline Eghtesad B & 1999 & USA & 45 & $19 / 26$ & $26 / 19$ & 22.3 \\
\hline Schumacher G & 2001 & Germany & 21 & NA & $14 / 7$ & NA \\
\hline Emre S & 2001 & USA & 22 & $3 / 14$ & $8 / 9$ & 28 \\
\hline Wang $X$ & 2005 & China & 22 & $19 / 3$ & $16 / 6$ & 15.5 \\
\hline Tamura S & 2005 & Japan & 5 & $2 / 3$ & $2 / 3$ & 20 \\
\hline Medici V & 2005 & Italy & 37 & $0 / 37$ & $17 / 20$ & 27.5 \\
\hline Dhawan A & 2005 & UK & 57 & $57 / 0$ & $22 / 35$ & 11.9 \\
\hline Petrasek J & 2007 & Czech Republic & 35 & $0 / 35$ & $26 / 9$ & 24.2 \\
\hline Marin C & 2007 & Spain & 14 & NA & NA & NA \\
\hline Sevmis S & 2008 & Turkey & 24 & NA & $7 / 17$ & 15.6 \\
\hline Martin AP & 2008 & Germany & 11 & $0 / 11$ & $6 / 5$ & 29.7 \\
\hline Pabón V & 2008 & France & 13 & $7 / 6$ & $8 / 5$ & 20 \\
\hline Markiewicz M & 2008 & Poland & 13 & $13 / 0$ & $12 / 1$ & 15.5 \\
\hline Cheng $\mathrm{F}$ & 2009 & China & 36 & $10 / 26$ & $20 / 16$ & NA \\
\hline Yoshitoshi EY & 2009 & Japan & 32 & $24 / 8$ & $17 / 15$ & 16.6 \\
\hline Peedikayil MC & 2013 & Saudi Arabia & 16 & NA & $7 / 9$ & 19.3 \\
\hline Ohya Y & 2013 & Japan & 8 & NA & $4 / 4$ & 15.7 \\
\hline Weiss KH & 2013 & Germany & 19 & $0 / 19$ & $13 / 6$ & 29.4 \\
\hline Guillaud 0 & 2014 & France & 121 & $46 / 75$ & $71 / 50$ & 22 \\
\hline Yagci MA & 2015 & Turkey & 9 & NA & $2 / 7$ & 18.4 \\
\hline Lankarani KB & 2016 & Iran & 107 & NA & $43 / 64$ & 20.8 \\
\hline Choudhary NS & 2018 & India & 18 & $0 / 18$ & $3 / 15$ & 32.4 \\
\hline Öcal R & 2018 & Turkey & 19 & $0 / 19$ & $5 / 14$ & 26 \\
\hline Total & & & 825 & $216 / 330$ & $393 / 366$ & 21.6 \\
\hline Percentage & & & & $39.5 / 60.5$ & $51.7 / 48.2$ & \\
\hline
\end{tabular}

NA, not available.

The general characteristics of the 28 studies included in the review were summarized in the table. 
Emre Turgut, et al.

Table 2. General characteristics of the transplant patients

\begin{tabular}{|c|c|c|c|c|c|c|c|c|c|}
\hline First author & $\begin{array}{c}\text { No. of } \\
\text { transplant }\end{array}$ & $\begin{array}{l}\text { Neurological } \\
\text { complication }\end{array}$ & $\begin{array}{l}\text { Kayser } \\
\text { Fleischer }\end{array}$ & $\begin{array}{l}\text { Living or } \\
\text { cadaveric } \\
\text { donation }\end{array}$ & $\begin{array}{l}\text { Acute } \\
\text { reject }\end{array}$ & $\begin{array}{c}\text { Chronic } \\
\text { reject }\end{array}$ & Re-transplant & $\begin{array}{c}\text { Follow-up } \\
\text { period (mon) }\end{array}$ & Mortality \\
\hline Rela M & 12 & NA & NA & NA & NA & NA & NA & NA & NA \\
\hline Schilsky M & 55 & 8 & 25 & NA & NA & NA & NA & 32.4 & 12 \\
\hline Bellary S & 39 & 9 & 20 & NA & 3 & 3 & 10 & NA & 8 \\
\hline Chen $\mathrm{CL}$ & 7 & 7 & 7 & NA & NA & NA & NA & 62.7 & NA \\
\hline Haberal M & 8 & 2 & 2 & $1 / 7$ & NA & NA & NA & NA & 3 \\
\hline Eghtesad B & 45 & 17 & 21 & NA & NA & NA & 11 & NA & 14 \\
\hline Schumacher G & 21 & 9 & NA & NA & NA & NA & NA & 62.4 & NA \\
\hline Emre S & 17 & NA & 2 & NA & 2 & 0 & 4 & 63.6 & 2 \\
\hline Wang $X$ & 22 & 9 & 19 & $22 / 0$ & 1 & 1 & 2 & 18.5 & 1 \\
\hline Tamura S & 5 & 1 & 4 & NA & NA & NA & NA & 40 & 1 \\
\hline Medici V & 37 & 10 & NA & NA & NA & NA & 4 & 64.6 & 10 \\
\hline Dhawan A & 10 & 51 & 6 & NA & 4 & 0 & 2 & NA & 2 \\
\hline Petrasek J & 31 & NA & 6 & NA & NA & NA & NA & NA & 5 \\
\hline Marin C & 14 & 4 & NA & NA & NA & NA & NA & 96 & 2 \\
\hline Sevmis $\mathrm{S}$ & 24 & 9 & 18 & $21 / 3$ & NA & NA & 1 & 21.7 & 5 \\
\hline Martin AP & 11 & 5 & 4 & NA & NA & NA & 2 & 56.8 & 1 \\
\hline Pabón V & 13 & 2 & 6 & $2 / 11$ & 1 & 1 & NA & 120 & 0 \\
\hline Markiewicz M & 11 & 11 & NA & $2 / 9$ & 2 & 0 & NA & 30.8 & 2 \\
\hline Cheng $\mathrm{F}$ & 36 & 15 & 31 & NA & NA & NA & NA & 45.2 & 9 \\
\hline Yoshitoshi EY & 32 & 4 & 25 & $32 / 0$ & NA & NA & 3 & 88 & 6 \\
\hline Peedikayil MC & 16 & 4 & 4 & $3 / 13$ & 4 & 1 & NA & 123 & 1 \\
\hline Ohya Y & 6 & NA & NA & $2 / 4$ & 0 & 1 & 1 & NA & 1 \\
\hline Weiss KH & 19 & 4 & NA & NA & 1 & 0 & 2 & NA & 5 \\
\hline Guillaud 0 & 121 & 29 & 69 & $4 / 117$ & 51 & 7 & 17 & 72 & 15 \\
\hline Yagci MA & 9 & NA & NA & $7 / 2$ & NA & NA & 2 & 36.6 & 0 \\
\hline Lankarani KB & 107 & 60 & NA & NA & 31 & 3 & 2 & 133.5 & 15 \\
\hline Choudhary NS & 18 & 3 & 7 & NA & 2 & 0 & NA & 15 & 2 \\
\hline Öcal R & 19 & 7 & NA & NA & NA & NA & NA & NA & NA \\
\hline Total & $765 / 825$ & $280 / 739$ & $276 / 566$ & $96 / 166$ & $99 / 455$ & $17 / 455$ & $63 / 553$ & 62.2 & $119 / 766$ \\
\hline Percentage & 92.7 & 37.8 & 48.7 & $36.6 / 63.3$ & 21.7 & 3.7 & 11.3 & & 15.5 \\
\hline
\end{tabular}

NA, not available.

The characteristics of patients who underwent liver transplantation in the studies were summarized in Table 2.

Results from 10 studies show that 96 (36.6\%) patients received from live donors while $166(63.4 \%)$ patients received cadaver donor transplants. In studies where transplant indications were given, $442(60.3 \%)$ cases were due to CLF and 290 (39.6\%) due to ALF. In 284 of 604 patients, (46.6\%) KF rings were present. Average biochemical levels were: bilirubin: $15.2(3-42.2) \mathrm{mg} / \mathrm{dL}$; standardized prothrombin time (international normalized ratio): 3.04 (1.5-10); urine copper: $1,819.2(256-4,119) \mu \mathrm{g}$; serum ceruloplasmin: 12.9 (7-22.2) $\mathrm{mg} / \mathrm{dL}$. Prior to their liver transplants, 247 out of 677 patients (36.4\%) displayed neurological symptoms. There were 6 studies examining neurological status both before and after transplant [1015]. When these studies were examined, a total of 101 patients had neurological complications before surgery. Neurological improvement was observed in 75 patients in the postoperative period. The studies highlighted a $74.2 \%$ post-transplant decrease in neurological symptoms over 101 patients. The details of these studies are summarized in Table 3. There were 19 studies that describe the periop- 
erative and long-term causes of death. The most common cause was due to sepsis and the multiple organ dysfunction syndrome. These were followed by primary non-function and surgical complications. The details of the causes of mortality in these studies are shared in Table 4. It was

Table 3. Neurological improvement in transplant patients

\begin{tabular}{|lccc}
\hline First author & $\begin{array}{c}\text { Number of } \\
\text { patients }\end{array}$ & Prior & After \\
\hline Wang X & 22 & $9(40.9)$ & $1(4.5)$ \\
\hline Chen CL & 7 & $7(100)$ & $1(14.2)$ \\
\hline Marin C & 14 & $4(28.5)$ & $1(7.1)$ \\
\hline Peedikayil MC & 16 & $4(25)$ & $0(0)$ \\
\hline Lankarani KB & 107 & $60(56)$ & $20(18.6)$ \\
\hline Eghtesad B & 45 & $17(37.7)$ & $3(6.6)$ \\
\hline Total & 211 & $101(47.8)$ & $26(12.3)$ \\
\hline
\end{tabular}

Values are presented as number only or number (\%).

A $74.2 \%$ improvement in neurological complications was seen when looking at six studies examining neurological status before and after transplantation. observed that mortality in liver transplants performed for WD was mostly due to early-stage causes. Overall survival rates for $1,2,3,5$ and 10 years were $84 \%, 82 \%, 81 \%, 81 \%$, and $80 \%$, respectively (Fig. $2-6$ ). In the 10 -year survival analysis, $80 \%$ of the mortalities were observed in the first

Table 4. Causes of post-transplant mortality

\begin{tabular}{|lcc|}
\hline \multicolumn{1}{|c}{ Cause of death } & No. of patients & Percentage \\
\hline Sepsis/MODS & 44 & 42.7 \\
\hline Primer non-function & 9 & 8.7 \\
\hline Surgical complications & 8 & 7.7 \\
\hline Cardiac & 7 & 6.8 \\
\hline B-cell lymphoma & 5 & 4.8 \\
\hline Rejection & 4 & 3.8 \\
\hline Haemorrhage & 3 & 2.9 \\
\hline Brain abscess & 3 & 2.9 \\
\hline Other reasons & 20 & 19.4 \\
\hline
\end{tabular}

MODS, multi-organ dysfunction syndrome.

The most common causes of mortality after liver transplantation for Wilson's disease are sepsis, MODS and other early complications.

\begin{tabular}{lr} 
Study & $\mathbf{n}$ \\
Choudhary et al. & 18 \\
Wang et al. & 22 \\
Sevmis et al. & 24 \\
Schilsky et al. & 55 \\
Yagci et al. & 9 \\
Tamura et al. & 5 \\
Cheng et al. & 36 \\
Martin et al. & 11 \\
Chen et al. & 7 \\
Emre et al. & 17 \\
Medici et al. & 37 \\
Guillaud et al. & 121 \\
Yoshitoshi et al. & 32 \\
Marin et al. & 14 \\
Pabón et al. & 13 \\
Peedikayil et al. & 16 \\
Lankarani et al. & 107 \\
Markiewicz et al. & 11 \\
Ohya et al. & 8 \\
Haberal et al. & 8 \\
Dhawan et al. & 10 \\
Weiss et al. & 19 \\
Petrasek et al. & 31 \\
Bellary et al. & 39 \\
Eghtesad et al. & 45 \\
Rela et al. & 12 \\
Total (fixed effects) & 727 \\
Toral (random effects) & 727 \\
& \\
\hline
\end{tabular}

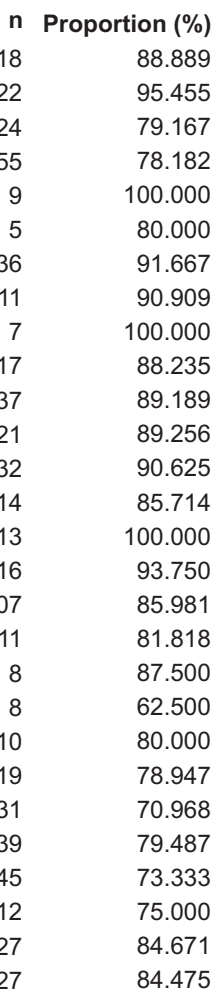

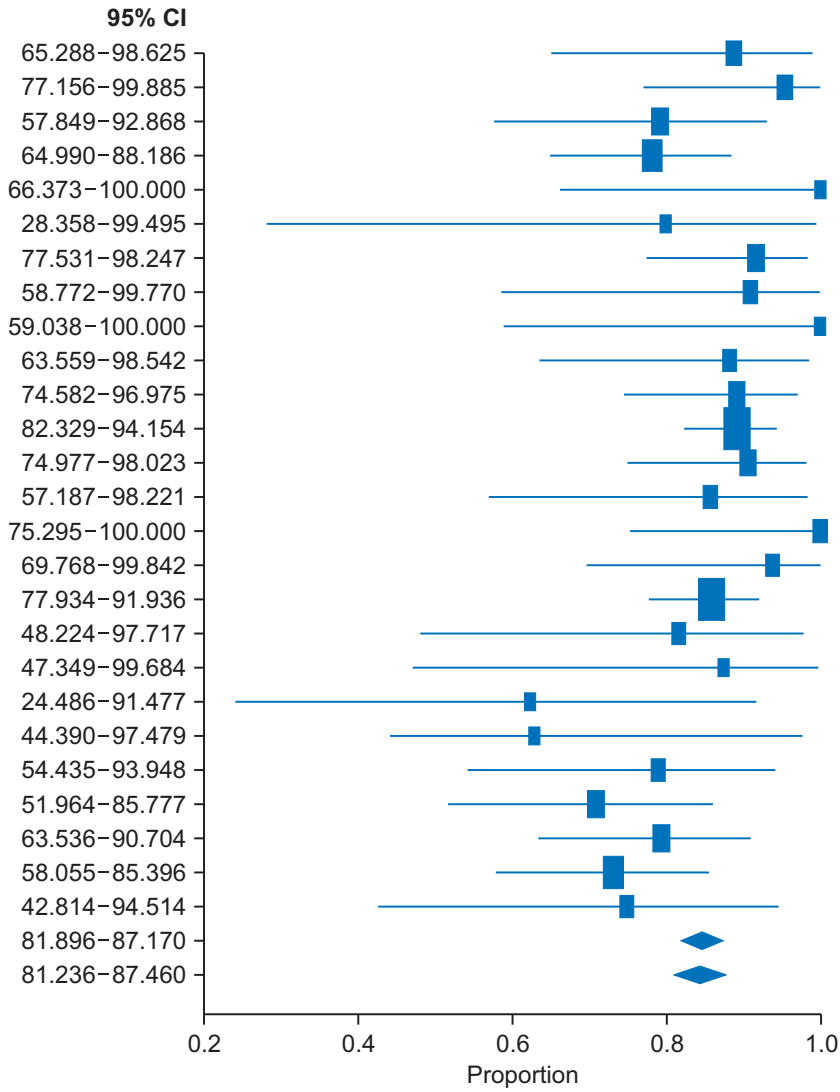

Test for heterogeneity

\begin{tabular}{|ll|}
\hline $\mathbf{Q}$ & $\mathbf{3 1 . 7 4 7 7}$ \\
Degree of freedom & 25 \\
Significance level & $\mathrm{p}=0.1654$ \\
$\mathbf{I}^{2}$ (inconsistency) & $21.25 \%$ \\
$\mathbf{9 5 \% ~ C l ~ f o r ~ I ~}$ & $0.00-51.45$ \\
\hline
\end{tabular}

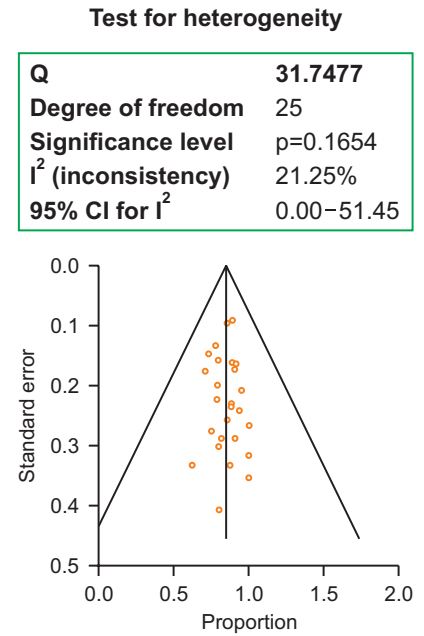

81.818

62.500

80.000

79.487

73.333

84.671

84.475

Fig. 2. One-year survival rate. $\mathrm{Cl}$, confidence interval. 
Study

Choudhary et al.

Schilsky et al.

Yagci et al.

Tamura et al.

Cheng et al.

Martin et al.

Chen et al.

Marin et al.

Pabón et al.

Peedikayil et al.

Markiewicz et al.

Ohya et al.

Haberal et al.

Dhawan et al.

Bellary et al.

Eghtesad et al.

Total (fixed effects)

Toral (random effects) n Proportion (\%)

88.889

74.545

100.000

80.000

86.111

90.909

100.000

85.714

100.000

93.750

81.818

87.500

62.500

80.000

79.487

73.333

82.035

82.980
$95 \% \mathrm{Cl}$

65.288-98.625 60.997-85.330 $66.373-100.000$ 28.358-99.495 70.503-95.332 58.722-99.770 $59.038-100.000-$ 57.187-98.221 $75.295-100.000$ 69.768-99.842 48.224-97.717 47.349-99.684 24.486-91.477 44.390-97.479 63.536-90.704 58.055-85.396 $77.390-86.078$ 77.776-87.617

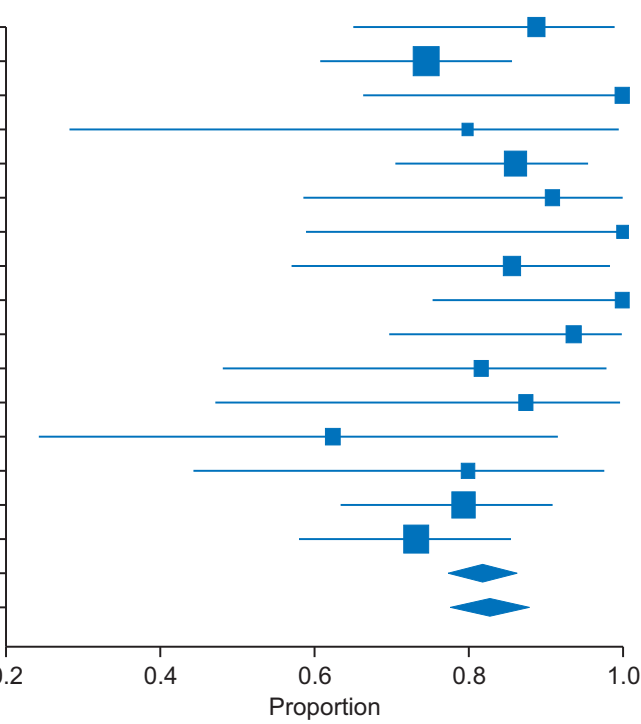

Test for heterogeneity

\begin{tabular}{|ll|}
\hline $\mathbf{Q}$ & $\mathbf{1 9 . 5 4 1 4}$ \\
Degree of freedom & 15 \\
Significance level & $\mathrm{p}=0.1902$ \\
$\mathrm{I}^{2}$ (inconsistency) & $23.24 \%$ \\
$\mathbf{9 5 \%} \mathrm{Cl}_{\text {for I }}{ }^{2}$ & $0.00-57.80$ \\
\hline
\end{tabular}

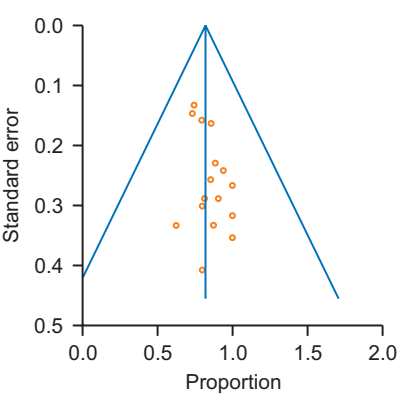

Fig. 3. Two-year survival rate. $\mathrm{Cl}$, confidence interval.

\section{Study}

Choudhary et al.

Schilsky et al.

Yagci et al.

Tamura et al.

Cheng et al.

Martin et al.

Chen et al.

Medici et al.

Marin et al.

Pabón et al.

Peedikayil et al.

Markiewicz et al.

Ohya et al.

Haberal et al.

Dhawan et al.

Bellary et al.

Eghtesad et al.

Total (fixed effects)

Toral (random effects) 342 n Proportion (\%)

88.889

72.727

100.000

80.000

83.333

90.909

100.000

83.784

85.714

100.000

93.750

81.818

87.500

62.500

80.000

79.487

73.333

81.594

82.410
$95 \% \mathrm{Cl}$ 65.288-98.625 $59.038-83.862-$ $66.373-100.000$ 28.358-99.495 67.188-93.628 58.722-99.770 $59.038-100.000-$ 67.986-93.807 57.187-98.221 $75.295-100.000$ 69.768-99.842 48.224-97.717 47.349-99.684 24.486-91.477 44.390-97.479 63.536-90.704 58.055-85.396 77.191-85.467 $77.556-86.786$

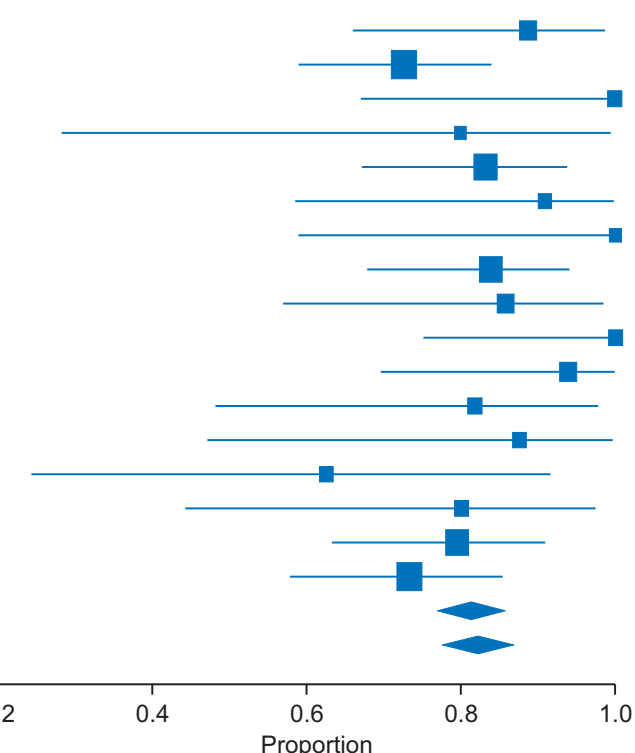

Test for heterogeneity

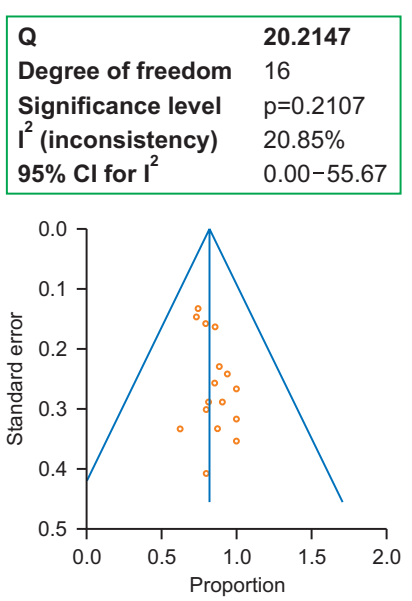

Fig. 4. Three-year survival rate. $\mathrm{Cl}$, confidence interval.

year, most probably within the perioperative period. No cases of recurrence were found in patients who had either cadaveric or live donor LT.

\section{DISCUSSION}

WD clearly presents as an illness pertaining to children and young adults. The mean age of the overall patient group was 21.4 years. Studies show the mean age for LT to be 15 years $(4-18)$ for children and 30 years for adults (19-68) [35-37]. In our study, $51.7 \%$ of the patients were woman and $48.2 \%$ man. Although the literature shows no significant difference between the genders in terms of WD diagnosis, studies indicate a significantly higher percentage of women with ALF due to WD [38,39]. In our study, we also saw that $61.7 \%$ of the patients who received LT due to 


\section{Study}

Cheng et al.

Martin et al.

Chen et al.

Medici et al.

Guillaud et al.

Yoshitoshi et al.

Marin et al.

Pabón et al.

Peedikayil et al.

Lankarani et al.

Ohya et al.

Haberal et al.

Dhawan et al.

Weiss et al.

Bellary et al.

Eghtesad et al.

Total (fixed effects)

Toral (random effects) n Proportion (\%)

75.000

90.909

85.714

75.676

86.777

84.375

85.714

100.000

93.750

82.243

87.500

62.500

80.000

63.158

79.487

73.333

81.364

80.927
$95 \% \mathrm{Cl}$

57.797-87.880 58.722-99.770

42.128-99.639

$58.801-88.227$

$79.416-92.249$

67.212-94.725

57.187-98.221

$75.295-100.000$

69.768-99.842

73.667-88.957

47.349-99.684

24.486-91.477

44.390-97.479

$38.358-83.711$

63.536-90.704

58.055-85.396

77.815-84.565

76.666-84.851

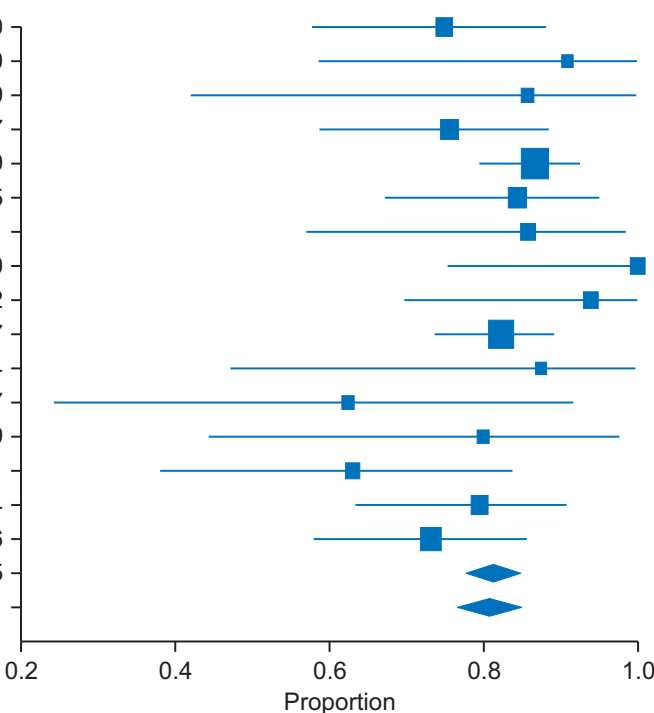

Test for heterogeneity

\begin{tabular}{|ll|}
\hline $\mathbf{Q}$ & $\mathbf{1 9 . 4 9 5 9}$ \\
Degree of freedom & 15 \\
Significance level & $\mathrm{p}=0.1921$ \\
$\mathrm{I}^{2}$ (inconsistency) & $23.06 \%$ \\
$\mathbf{9 5 \%} \mathrm{Cl}_{\text { for I }}{ }^{2}$ & $0.00-57.69$ \\
\hline
\end{tabular}

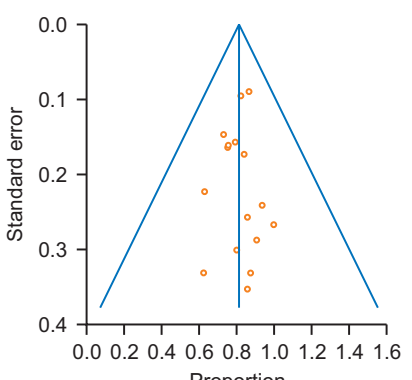

Proportion

Fig. 5. Five-year survival rate. $\mathrm{Cl}$, confidence interval.

Study

Martin et al.

Medici et al.

Guillaud et al.

Yoshitoshi et al.

Pabón et al.

Peedikayil et al.

Dhawan et al

Bellary et al.

Eghtesad et al.

Total (fixed effects)

Toral (random effects) 324 n Proportion (\%)

90.909

59.459

86.777

78.125

100.000

87.500

80.000

79.487

68.889

80.212

80.010
$95 \% \mathrm{Cl}$

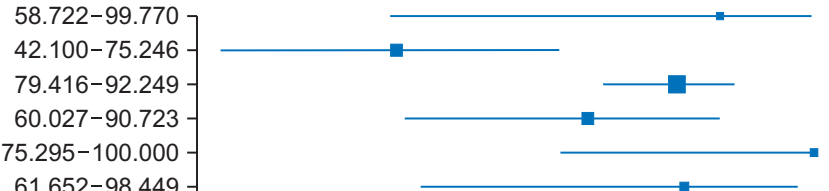

61.652-98.449-

44.390-97.479

63.536-90.704

$53.351-81.834$

75.521-84.355

$71.598-87.261$

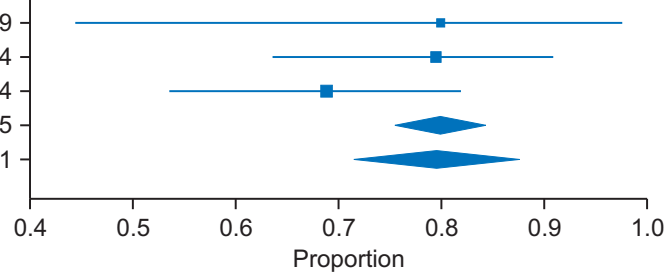

Test for heterogeneity

\begin{tabular}{|ll|}
\hline $\mathbf{Q}$ & $\mathbf{2 2 . 0 5 8 7}$ \\
Degree of freedom & 8 \\
Significance level & $\mathrm{p}=0.0048$ \\
$\mathbf{I}^{2}$ (inconsistency) & $63.73 \%$ \\
$\mathbf{9 5 \%} \mathrm{Cl}$ for I & $25.65-82.31$ \\
\hline
\end{tabular}

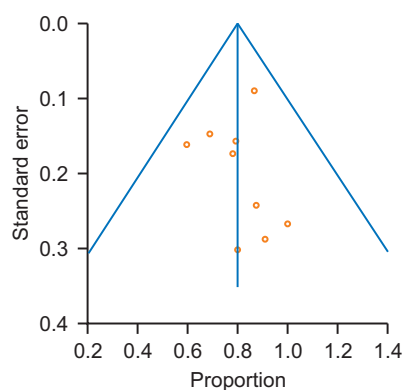

Fig. 6. Ten-year survival rate. $\mathrm{Cl}$, confidence interval.

ALF were woman compared to $38.2 \%$ man $(p<0.0001)$. Further research is needed to determine the reasons why ALF is more common among women who suffer from WD.

Since the disease is caused by a defect in the body's metabolism of copper, it causes symptoms related to excess copper accumulation in various tissues, especially the liver. Initially, certain patients may be diagnosed with symptoms of ALF or decompensated cirrhosis, while in other patients serious neurological symptoms may be more evident. The type of gene mutation may be important in identifying the presenting symptoms. While missense mutation in the gene is associated with older patients and prominent neurological symptoms, deletion mutation appears to be associated with younger patients and prominent hepatic symptoms $[39,40]$. However, this delineation is not absolute as most patients show a mix of both neurological and hepatic symptoms. Therefore, WD diagnosis should be made using a combination of laboratory tests and clinical findings. Twenty-four hour urine copper and liver copper concentrations, serum ceruloplasmin, ATP7B gene mutation, neurological symptoms, brain magnetic resonance imaging and hemolytic anemia are all important for the diagnosis of 
WD. KF rings are seen in only $50 \%$ of cases [41] and in our study, this rate was $46 \%$. Diagnosis of WD in patients who suffer from ALF, where clinical findings and laboratory tests are less reliable and non-specific, is also more problematic. Most tests related to copper metabolism are not available in an emergency. In addition, serum ceruloplasmin levels were found to be unhelpful in the diagnosis of WD in 5 patients with idiopathic ALF $[42,43]$. In a study performed on 16 ALF patients to overcome this difficulty, a serum alkaline phosphatase to total serum bilirubin ratio of less than 2 , along with a serum aspartate aminotransferase to serum alanine aminotransferase ratio of greater than 2.2 were found to be $100 \%$ sensitive and specific for WD-related ALF [44].

Significantly, LT immediately corrects the defect in copper metabolism. The normalization of serum ceruloplasmin levels post-transplantation usually occurs within the first month. As excess copper leaves the body relatively more slowly, it can take up to 6-9 months for urine copper levels to return to normal. In patients with a KF ring, the ring disappears completely in $60 \%$ of transplant patients, while a gradual fading is seen among other patients $[45,46]$.

Another important post-transplant parameter is the improvement in neurological status. In this systematic review, the rate of neurological recovery after LT was also found to be high at $74.2 \%$. However, whether or not neurological symptoms alone should be an indication for transplantation, still remains unclear. There are very few cases in the literature of a patient undergoing LT due to neurological symptoms while displaying normal liver functions $[47,48]$. In the study by Wang et al. [15], 88.9\% neurological recovery was recorded. Eghtesad et al. [11] reported a $58.8 \%$ neurological improvement in their study, but advocated transplantation before symptoms became irreversible.

Factors affecting survival rates after $L T$ related to WD, in the literature, are uncommon. No conclusive results were found in studies investigating the effect of factors such as age, sex, ALF or CLF. Medici et al. [8] reported the only factor affecting the survival rate to be neurological status and found that the survival rate of patients with severe neurological symptoms was significantly lower. Wang et al. [15] came to the same conclusion in their study. However, in this systematic review, long-term results were found to be very successful, independent of neurological involvement. According to this analysis, the most significant parameter affecting mortality rates is perioperative patient loss. In conclusion, although neurological status is not an indication for transplantation alone, it should be remembered that the reversal of symptoms in patients with persistent neurological involvement is far more problematic; therefore, such patients may have a lower quality of life post-LT, indirectly leading to an increase in mortality rates over the long term.

A further concern for WD is the potential transmission of the gene mutation in the case of LT from a live family donor, causing a recurrence of the disease. No such recurrence was found in our analysis of the live-donor transplant patient data. In fact, one study showed that none of the 11 children (9 ALF, 2 CLF) who underwent live-donor liver transplants from their parents had recurrence during the average follow-up period of 31 months [49]. It seems that since WD shows autosomal recessive inheritance, live donor liver transplants can be safely performed from individuals who carry heterozygous gene and have normal urine copper and serum ceruloplasmin levels.

Examination of the average survival rates for $1,2,3,5$, and 10 years reveal a success rate of $82 \%, 81 \%, 81 \%$, and $80 \%$ respectively. Arnon et al. [6] in their study reported good survival rates for 1-year and 5-year terms as well as a better survival rate for WD related LT patients compared with transplant patients related to other illnesses. Higher survival rates can be attributed to the relatively young age for transplantation, fewer co-morbidities, and no disease recurrence. Similar results were obtained in our study.

This study has some limitations. First, most of the studies in the literature on liver transplants for WD are retrospective. The number of detailed prospective studies is few. Second, the number of studies providing sufficient detail in the preoperative and postoperative follow-up of neurological symptoms is not sufficient.

\section{CONCLUSIONS}

Liver transplants for WD have a higher survival rate than those for other indications. In addition, there is an improvement in neurological symptoms at a rate of $74.2 \%$ after transplantation. Mortality was mostly perioperative and was largely due to sepsis and multiple organ dysfunction syndrome. One-year, five-year and ten-year survival rates were similar. Perioperative mortality seems to be the most important parameter in determining long-term survival rates.

\section{FUNDING}

There was no funding related to this study. 


\section{CONFLICT OF INTEREST}

All authors have no conflicts of interest to declare.

\section{ORCID}

Emre Turgut https://orcid.org/0000-0001-8196-1871 Cemalettin Aydin

https://orcid.org/0000-0002-7839-3495

Cuneyt Kayaalp https://orcid.org/0000-0003-4657-2998

Sezai Yilmaz https://orcid.org/0000-0002-8044-0297

\section{AUTHORS' CONTRIBUTIONS}

Conceptualization: ET, CA. Data curation: CK. Formal analysis: CA, CK. Investigation: ET, CA, CK. Methodology: ET, CK. Project administration: CK, SY. Resources: ET, CA, CK. Software: ET, CK. Supervision: SY. Validation: SY. Visualization: ET. Writing - original draft: ET. Writing - review \& editing: $\mathrm{CA}, \mathrm{CK}$.

\section{REFERENCES}

1. Ferenci P. Regional distribution of mutations of the ATP7B gene in patients with Wilson disease: impact on genetic testing. Hum Genet 2006;120:151-159.

2. Schoen RE, Sternlieb I. Clinical aspects of Wilson's disease. Am J Gastroenterol 1990;85:1453-1457.

3. Ala A, Schilsky ML. Wilson disease: pathophysiology, diagnosis, treatment, and screening. Clin Liver Dis 2004;8:787-805, viii.

4. Schilsky ML. Liver transplantation for Wilson's disease. Ann N Y Acad Sci 2014;1315:45-49.

5. DuBois RS, Rodgerson DO, Martineau G, Shroter G, Giles G, Lilly J, et al. Orthotopic liver transplantation for Wilson's disease. Lancet 1971;1:505-508.

6. Arnon R, Annunziato R, Schilsky M, Miloh T, Willis A, Sturdevant $\mathrm{M}$, et al. Liver transplantation for children with Wilson disease: comparison of outcomes between children and adults. Clin Transplant 2011;25:E52-E60.

7. Guillaud O, Dumortier J, Sobesky R, Debray D, Wolf P, Vanlemmens $\mathrm{C}$, et al. Long term results of liver transplantation for Wilson's disease: experience in France. J Hepatol 2014;60: 579-589.

8. Medici V, Mirante VG, Fassati LR, Pompili M, Forti D, Del Gaudio M, et al.; Monotematica AISF 2000 OLT Study Group. Liver transplantation for Wilson's disease: the burden of neurological and psychiatric disorders. Liver Transpl 2005;11:
1056-1063.

9. Bellary S, Hassanein T, Van Thiel DH. Liver transplantation for Wilson's disease. J Hepatol 1995;23:373-381.

10. Chen CL, Chen YS, Lui CC, Hsu SP. Neurological improvement of Wilson's disease after liver transplantation. Transplant Proc 1997;29:497-498.

11. Eghtesad B, Nezakatgoo N, Geraci LC, Jabbour N, Irish WD, Marsh W, et al. Liver transplantation for Wilson's disease: a single-center experience. Liver Transpl Surg 1999;5:467-474.

12. Lankarani KB, Malek-Hosseini SA, Nikeghbalian S, Dehghani M, Pourhashemi M, Kazemi K, et al. Fourteen years of experience of liver transplantation for Wilson's disease; a report on 107 cases from Shiraz, Iran. PLoS One 2016;11:e0167890.

13. Marin C, Robles R, Parrilla G, Ramírez P, Bueno FS, Parrilla P. Liver transplantation in Wilson's disease: are its indications established? Transplant Proc 2007;39:2300-2301.

14. Peedikayil MC, Al Ashgar HI, Al Mousa A, Al Sebayel M, Al Kahtani K, Alkhail FA. Liver transplantation in Wilson's disease: single center experience from Saudi Arabia. World J Hepatol 2013;5:127-132.

15. Wang XH, Cheng F, Zhang F, Li XC, Kong LB, Li GQ, et al. Living-related liver transplantation for Wilson's disease. Transpl Int 2005;18:651-656.

16. Cheng F, Li GQ, Zhang F, Li XC, Sun BC, Kong LB, et al. Outcomes of living-related liver transplantation for Wilson's disease: a single-center experience in China. Transplantation 2009;87:751-757.

17. Choudhary NS, Saigal S, Saraf N, Rastogi A, Goja S, Bhangui $P$, et al. Outcome of living donor liver transplantation for Wilson's disease in adults: a single center experience. J Clin Exp Hepatol 2018;8:132-135.

18. Dhawan A, Taylor RM, Cheeseman P, De Silva P, Katsiyiannakis L, Mieli-Vergani G. Wilson's disease in children: 37-year experience and revised King's score for liver transplantation. Liver Transpl 2005;11:441-448.

19. Emre S, Atillasoy EO, Ozdemir S, Schilsky M, Rathna Varma $\mathrm{CV}$, Thung SN, et al. Orthotopic liver transplantation for Wilson's disease: a single-center experience. Transplantation 2001;72:1232-1236.

20. Haberal M, Moray G, Karakayali H, Arslan G, Boyacioglu S, Baysal C, et al. Liver transplantation for Wilson's cirrhosis: one center's experience. Transplant Proc 1999;31:3160-3161.

21. Markiewicz-Kijewska M, Szymczak M, Ismail H, Prokurat $S$, Teisseyre J, Socha P, et al. Liver transplantation for fulminant Wilson's disease in children. Ann Transplant 2008;13:28-31.

22. Martin AP, Bartels M, Redlich J, Hauss J, Fangmann J. A single-center experience with liver transplantation for Wilson's disease. Clin Transplant 2008;22:216-221. 
Emre Turgut, et al.

23. Öcal R, Öcal S, Kırnap M, Moray G, Haberal M. Complications of liver transplant in adult patients with the hepatic form of Wilson disease. Exp Clin Transplant 2018;16 Suppl 1:38-40.

24. Ohya $Y$, Okajima H, Honda M, Hayashida S, Suda H, Matsumoto $S$, et al. Re-evaluation of the indications for liver transplantation in Wilson's disease based on the outcomes of patients referred to a transplant center. Pediatr Transplant 2013;17: 369-373.

25. Pabón V, Dumortier J, Gincul R, Baulieux J, Ducerf C, Trépo C, et al. Long-term results of liver transplantation for Wilson's disease. Gastroenterol Clin Biol 2008;32:378-381.

26. Petrasek J, Jirsa M, Sperl J, Kozak L, Taimr P, Spicak J, et al. Revised King's College score for liver transplantation in adult patients with Wilson's disease. Liver Transpl 2007;13:55-61.

27. Rela M, Heaton ND, Vougas V, McEntee G, Gane E, Farhat B, et al. Orthotopic liver transplantation for hepatic complications of Wilson's disease. Br J Surg 1993;80:909-911.

28. Schilsky ML, Scheinberg IH, Sternlieb I. Liver transplantation for Wilson's disease: indications and outcome. Hepatology 1994;19:583-587.

29. Schumacher G, Platz KP, Mueller AR, Neuhaus R, Luck W, Langrehr JM, et al. Liver transplantation in neurologic Wilson's disease. Transplant Proc 2001;33:1518-1519.

30. Sevmis S, Karakayali H, Aliosmanoglu I, Yilmaz U, Ozcay F, Torgay A, et al. Liver transplantation for Wilson's disease. Transplant Proc 2008;40:228-230.

31. Tamura S, Sugawara Y, Kishi Y, Akamatsu N, Kaneko J, Makuuchi M. Living-related liver transplantation for Wilson's disease. Clin Transplant 2005;19:483-486.

32. Weiss KH, Schäfer M, Gotthardt DN, Angerer A, Mogler C, Schirmacher $\mathrm{P}$, et al. Outcome and development of symptoms after orthotopic liver transplantation for Wilson disease. Clin Transplant 2013;27:914-922.

33. Yagci MA, Tardu A, Karagul S, Ertugrul I, Ince V, Kirmizi S, et al. Influence of liver transplantation on neuropsychiatric manifestations of Wilson disease. Transplant Proc 2015;47:14691473.

34. Yoshitoshi EY, Takada Y, Oike F, Sakamoto S, Ogawa K, Kanazawa $\mathrm{H}$, et al. Long-term outcomes for 32 cases of Wilson's disease after living-donor liver transplantation. Transplantation 2009;87:261-267.

35. Ala A, Borjigin J, Rochwarger A, Schilsky M. Wilson disease in septuagenarian siblings: raising the bar for diagnosis. Hepa- tology 2005;41:668-670.

36. Arnon R, Kerkar N, Davis MK, Anand R, Yin W, González-Peralta RP; SPLIT Research Group. Liver transplantation in children with metabolic diseases: the studies of pediatric liver transplantation experience. Pediatr Transplant 2010;14:796-805.

37. Gitlin JD. Wilson disease. Gastroenterology 2003;125:18681877.

38. Ala A, Walker AP, Ashkan K, Dooley JS, Schilsky ML. Wilson's disease. Lancet 2007;369:397-408.

39. Walshe JM. Cause of death in Wilson disease. Mov Disord 2007;22:2216-2220.

40. Scheinberg IH, Sternlieb I. Wilson disease and idiopathic copper toxicosis. Am J Clin Nutr 1996;63:842S-845S.

41. Roberts EA, Schilsky ML; American Association for Study of Liver Diseases (AASLD). Diagnosis and treatment of Wilson disease: an update. Hepatology 2008;47:2089-2111.

42. McCullough AJ, Fleming CR, Thistle JL, Baldus WP, Ludwig J, McCall JT, et al. Diagnosis of Wilson's disease presenting as fulminant hepatic failure. Gastroenterology 1983;84:161-167.

43. Schilsky ML, Sternlieb I. Overcoming obstacles to the diagnosis of Wilson's disease. Gastroenterology 1997;113:350-353.

44. Korman JD, Volenberg I, Balko J, Webster J, Schiodt FV, Squires RH Jr, et al.; Pediatric and Adult Acute Liver Failure Study Groups. Screening for Wilson disease in acute liver failure: a comparison of currently available diagnostic tests. Hepatology 2008;48:1167-1174.

45. Kasahara M, Takada Y, Egawa H, Fujimoto Y, Ogura Y, Ogawa K, et al. Auxiliary partial orthotopic living donor liver transplantation: Kyoto University experience. Am J Transplant 2005;5: 558-565.

46. Schilsky ML. Diagnosis and treatment of Wilson's disease. Pediatr Transplant 2002;6:15-19.

47. Bax RT, Hässler A, Luck W, Hefter H, Krägeloh-Mann I, Neuhaus $P$, et al. Cerebral manifestation of Wilson's disease successfully treated with liver transplantation. Neurology 1998; 51:863-865

48. Mason AL, Marsh W, Alpers DH. Intractable neurological Wilson's disease treated with orthotopic liver transplantation. Dig Dis Sci 1993;38:1746-1750.

49. Asonuma K, Inomata $\mathrm{Y}$, Kasahara M, Uemoto S, Egawa $\mathrm{H}$, Fujita $S$, et al. Living related liver transplantation from heterozygote genetic carriers to children with Wilson's disease. Pediatr Transplant 1999;3:201-205. 